
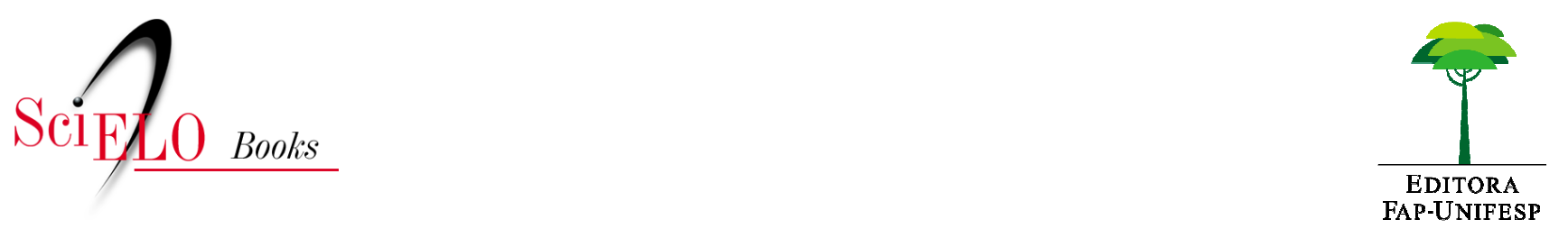

\title{
2 - A formação profissional no contexto das Diretrizes Curriculares Nacionais para o curso de medicina
}

\author{
Regina Celes de Rosa Stella \\ Rosana Fiorini Puccini
}

\section{SciELO Books / SciELO Livros / SciELO Libros}

STELLA, RCR., and PUCCINI, RF. A formação profissional no contexto das Diretrizes Curriculares nacionais para o curso de medicina. In PUCCINI, RF., SAMPAIO, LO., and BATISTA, NA., orgs. A formação médica na Unifesp: excelência e compromisso social [online]. São Paulo: Editora Unifesp, 2008. pp. 53-69. ISBN 978-85-61673-66-6. Available from SciELO Books 〈http://books.scielo.org〉.

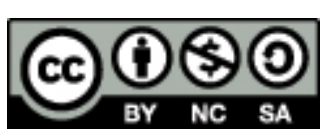

All the contents of this work, except where otherwise noted, is licensed under a Creative Commons Attribution-Non Commercial-ShareAlike 3.0 Unported.

Todo o conteúdo deste trabalho, exceto quando houver ressalva, é publicado sob a licença Creative Commons Atribuição Uso Não Comercial - Partilha nos Mesmos Termos 3.0 Não adaptada.

Todo el contenido de esta obra, excepto donde se indique lo contrario, está bajo licencia de la licencia Creative Commons Reconocimento-NoComercial-CompartirIgual 3.0 Unported. 


\title{
A Formação Profissional no Contexto das Diretrizes Curriculares Nacionais para o Curso de Medicina
}

\author{
Regina Celes de Rosa Stella e \\ Rosana Fiorini Puccini
}

As Diretrizes Curriculares Nacionais (DCN) para os cursos de graduação, na área da saúde (Brasil, 200I), constituem mudança paradigmática do processo de educação superior, de um modelo flexneriano, biomédico e curativo para outro, orientado pelo binômio saúde-doença em seus diferentes níveis de atenção, com açôes de promoção, prevenção, recuperação e reabilitação da saúde, na perspectiva da integralidade da assistência; de uma dimensáo individual para uma dimensáo coletiva; de currículos rígidos, compostos por disciplinas cada vez mais fragmentadas, com priorização de atividades teóricas, para currículos flexíveis, modulares, dirigidos para a aquisição de um perfil e respectivas competências profissionais, os quais exigem modernas metodologias de aprendizagem, habilidades e atitudes, além de múltiplos cenários de ensino.

Aprovadas em 200I, as diretrizes encontram ainda dificuldades e resistências para sua implementação. As dificuldades são inerentes à introdução de novos paradigmas. As resistências, na sua maioria, 
situam-se intramuros, advindas de uma parte do corpo docente que sente a proposta de integraçáo como uma ameaça à importância de sua disciplina e considera o hospital universitário e seus ambulatórios de especialidades como único ou principal locus do ensino.

Uma outra ordem de dificuldades é aquela inerente ao estabelecimento de um diálogo, de uma interaçáo com o mundo do trabalho, no caso representado pelo Sistema Único de Saúde (sus) e suas unidades próprias de atenção à saúde. Além disso, existe a necessidade de uma nova pactuaçáo com prestadores de serviço ao sus, como os hospitais de ensino; a estes se procura dar maior funcionalidade, inclusive com a indicação de fluxos de referência e contra-referência, estabelecendose como porta de entrada no sistema os centros de atençáo básica.

A compreensão do alcance dessas diretrizes e das novas práticas profissionais derivadas demanda uma contextualização de seu processo de elaboração.

A construção das DCN dos cursos de graduação tem origem nos questionamentos sobre o ensino superior, iniciados na década de I960, entre os quais se destaca o seu isolamento do mundo do trabalho, formando profissionais com perfil não adequado às necessidades sociais (Santos, I 995). Essa discussão aprofunda-se no último quartel do século xx, na Europa e nas Américas, gerando propostas de revisão curricular e de novas práticas pedagógicas, orientadas para a resolução do "conflito entre instrução e formação, entre adestramento e educação", nos termos da reflexão feita por Antonio Manoel dos Santos Silva sobre a universidade no limiar do século xxi (Silva, I999).

Entre I945 e 1964, o Brasil vive um período de experimentação democrática, marcado pelo nacionalismo desenvolvimentista e por uma aliança com os trabalhadores na tentativa de formação de uma base social. Cria-se no Ministério da Educação o Instituto Superior de Estudos Brasileiros - ISEB (I955-I964) -, que congregou vários intelectuais brasileiros, como Cândido Motta Filho, Anísio Teixeira e Hélio Jaguaribe (Toledo, 2005). O ISEB tornou-se um verdadeiro 
centro de formação política e ideológica, de origem democrática e caráter reformista, que produziu pesquisas, cursos regulares, seminários e debates públicos. Nele conviveram liberais, social-democratas, comunistas e católicos progressistas. Somente nos últimos anos antes de sua desativação, quando dirigido pelo filósofo Álvaro Vieira Pinto e pelo historiador Nelson Werneck Sodré, ocorre uma homogeneização ideológica, com o predomínio de tendências marxistas, privilegiando-se o debate das reformas sociais e econômicas defendidas pelo movimento nacionalista e pelo governo João Goulart (Toledo, I 997).

É nesse ambiente que Paulo Freire ensina e desenvolve sua teoria, destacando-se entre os educadores brasileiros proponentes de mudanças. Em sua tese de concurso para a cadeira de História e Filosofia da Educação na Escola de Belas-Artes de Pernambuco (Freire, 200I), escrita em 1959, faz uma reflexão sobre o antagonismo entre o momento histórico de uma sociedade que se democratiza e necessita formar cidadáos, e o ensino, centrado na palavra desvinculada da realidade que deveria representar, pobre de atividades em que o educando ganharia experiência pelo fazer; sobre o antagonismo entre uma escola que não permite a discussão, o gosto pela pesquisa ou a recriação do conhecimento, e a necessidade de formar indivíduos com espírito crítico; sobre o antagonismo entre uma escola que se alheia da discussão sobre a realidade da vida, do entorno e da nação, e o desejo de desenvolver no educando a "criticidade de sua consciência", incutindo-lhe o "sentimento de dever cívico de preocupação com o outro, com o coletivo".

$\mathrm{Na}$ conclusão de sua tese, Freire apresenta consideraçóes pertinentes e ainda atuais, das quais citamos duas:

[...] para ter força de mudança, para ser "agente de los cambios sociales", na expressão de Mannheim, é necessário ao processo educativo estabelecer relação de organicidade com a contextura da sociedade a que se aplica; 
[...] finalmente, a revisão de nosso processo educativo não pode ser parcial porque é todo ele que está inadequado e é todo ele, em conjunto, em bloco, que a cultura em elaboração precisa.

No período da ditadura militar (I964-I984), essas idéias são reprimidas, e as reformas da educação - como a criação de departamentos e institutos segundo as áreas de conhecimento - restringem-se aos aspectos organizacionais. Os currículos continuam a ser rigidamente definidos pelo Conselho Federal de Educação, e a segmentação entre formação básica e profissionalizante é acentuada.

Com a retomada da democracia, a discussão é reaberta. Em I996, é promulgada a nova Lei de Diretrizes e Bases da Educação, proposta por Darcy Ribeiro, a qual concede autonomia didático-científica às universidades, assegurando-lhes, entre outras atribuiçôes, a de "fixar os currículos de seus cursos e programas, observadas as diretrizes gerais pertinentes" (Diário Oficial, 23 dez. 1996).

A síntese de movimentações semelhantes em outros países encontra-se no texto básico elaborado para a Conferência Mundial sobre Educação Superior, realizada pela Unesco em I998:

Às vésperas do novo século, ocorre uma diversificação do ensino superior e uma demanda sem precedente nessa área, bem como uma crescente conscientização de sua vital importância para o desenvolvimento sociocultural e econômico e para a construção do futuro, em razão do que as geraçôes mais novas deverão estar munidas de novos conhecimentos, destrezas e ideais.

Essa conferência produz extenso documento que contempla uma formação responsável, cidadã e ética; propõe também a capacitação para a educação permanente e o conhecimento do método científico, com suporte em novas práticas pedagógicas que facilitem a aquisição de competências, habilidades e treinamento para trabalhar em grupos. 
As discussóes e propostas sobre o ensino médico ocorrem na confluência entre os movimentos educacionais e os específicos de reformulação no campo de atuação dos profissionais de saúde.

$\mathrm{Na}$ década de I970, o mundo passa por uma crise no modelo de atenção e financiamento médicos. A tecnificação crescente da medicina, aliada a uma prática médica curativa e aos interesses privados havia sido responsável por um crescimento desordenado de custos que não resultarou em melhoria - condizente com a inversão financeira - na assistência e nas condiçóes de saúde da população.

Em I978, a Organização Mundial da Saúde (oMs) realiza em Alma-Ata (oMs, I978) uma conferência que reafirma o conceito de saúde como o estado de completo bem-estar físico, mental e social, e não simplesmente como a ausência de doença ou enfermidade, direito fundamental de todo ser humano. Propugna pela inserção, nos programas governamentais, dos cuidados primários em saúde, os quais têm como base os resultados da pesquisa social, biomédica e de saúde pública sobre doenças prevalentes e devem conter um leque de açóes educativas, preventivas, curativas e de reabilitação.

No panorama nacional, profissionais da área de saúde organizamse em um movimento pela Reforma Sanitária, "gerado na luta contra o autoritarismo e pela ampliação dos direitos sociais” (Paim, I 992), propondo mudanças em todo o arcabouço jurídico-institucional vigente e contemplando a ampliação do conceito de saúde, segundo os preceitos da mencionada reforma. Esse movimento estrutura-se nas universidades, com o apoio dos departamentos de medicina preventiva recém-criados em algumas instituiçóes como USP, Unicamp, UERJ e EPM, hoje Unifesp, e também da Fiocruz, sendo abraçado por outros setores da sociedade e pelo partido de oposição da época - o Movimento Democrático Brasileiro. A mobilização estudantil teve um papel fundamental na propagação das idéias e fez com que muitos jovens começassem a se incorporar a essa nova maneira de ver a saúde (Radis - Comunicação em Saúde, 2002). 
O marco histórico nesse processo foi, sem dúvida, a viII Conferência Nacional de Saúde, organizada por Sérgio Arouca em março de 1986, à qual compareceram aproximadamente quatro mil representantes de diversos setores da sociedade (Andrade et al., 2000). As conclusôes provenientes desse encontro proporcionaram as bases para a elaboração da seção referente à saúde na Constituição da República Federativa do Brasil (Brasil, I988), promulgada em I988. Ao definir a saúde como "direito de todos e dever do Estado" e criar o sus, os dispositivos contidos naquela seção estabeleceram um marco na história da saúde pública brasileira. O sus foi uma grande conquista, principalmente no que se refere ao resgate da cidadania. Desde I 988 está implantado em todo o país e tem avançado na consolidaçáo de seus programas e princípios. A adequação do processo de formação de recursos humanos para o trabalho em saúde tem sido fundamental para essa consolidação.

Em paralelo à reformulação do modelo de atenção à saúde, na década de I980, iniciam-se no Brasil e em outros países da América Latina projetos de integração docente-assistencial, conhecidos pela sigla IDA, envolvidos em uma experiência pioneira. A partir de I985, com apoio da Fundação Kellogg, esses projetos passam a se articular por meio de uma rede - a Rede IDA.

Embora de pouco impacto no interior dos cursos de medicina, pois circunscritos aos departamentos de medicina preventiva, saúde pública ou pediatria, permitiram uma reflexão sobre seus acertos e erros, evoluindo para novas propostas. Entre essas, destaca-se o projeto UNI - Uma Nova Iniciativa na Formação dos Profissionais de Saúde: União com a Comunidade -, também financiado pela Fundação Kellogg e contando com grande apoio da Organização PanAmericana da Saúde (opas). Esse projeto apresentava como objetivos: “a) contribuir para a reorientação da formação profissional ao nível dos cursos de graduação; b) fortalecer a construção de sistemas locais de saúde; c) promover o desenvolvimento comunitário em matéria de 
saúde" (Almeida, I999). No Brasil, foram indicadas seis escolas, de um total de 26 participantes.

$\mathrm{Na}$ década de I990, os projetos IDA e UNI se mantiveram em atividade e se institucionalizaram, enquanto outros tiveram dificuldades em função do término dos financiamentos. Esse conjunto de experiências, de forma articulada, manteve a realização de encontros e congressos organizados pela Rede IDA, buscando aprofundar as discussóes e contextualizar o trabalho diante da nova realidade das políticas de saúde do país, sobretudo com a criação do sus e da legislação que garantia o controle social. Ocorre uma implementação do processo de aproximação ensino-serviço-comunidade, e a rede, agregando esse conjunto de projetos e experiências, se estabelece como Rede Unida (Feuerwerker et al., [s.d.]), desempenhando importante papel nas discussóes sobre educação nos cursos de graduação da área da saúde.

Em razão das evidências sobre a necessidade de mudanças na educação superior e das demandas específicas na área da saúde, no recorte do ensino médico, a World Federation of Medical Education (wFME) realizou em I988 a Conferência Mundial de Educação Médica na cidade de Edimburgo. As cinco federaçóes componentes da wFME - África, Américas, Europa, Oriente Médio e Pacífico Ocidental organizaram as respostas de seus setores sobre os 32 questionamentos diagnósticos que compuseram a base para a conferência. A discussão desses resultados gerou uma proposta de reorientação para o modelo de formação médica, conhecida como Declaração de Edimburgo (The Edinburgh Declaration, I988).

Para atender à convocação da WFME, a Federação Pan-Americana de Faculdades e Escolas de Medicina (Fepafem) decidiu dar andamento ao projeto "Educação Médica nas Américas - EMA", já esboçado no xxvi Congresso Brasileiro de Educação Médica. A coordenação ficou a cargo da Associação Brasileira de Educação Médica (ABEM) e o patrocínio proveio da Fundação Kellogg, que paralelamente "apoiou outros estudos que permitiram melhor conhecimento da situação do 
ensino de Enfermagem, Odontologia e Administração dos Serviços de Saúde na América Latina" (Chaves \& Rosa, I990).

As análises produzidas na primeira fase resultaram na contribuição das Américas à Conferência Mundial de Edimburgo. Na segunda fase delinearam-se os planos para correçáo dos problemas detectados: desarticulação entre graduação, pós-graduação e educação continuada - em relação a esta última modalidade, era certo que crescera desordenadamente e convertera-se em objeto de consumo mercantilista; currículo hospitalocêntrico, segmentado entre ciências básicas e profissionalizantes, com excessiva subdivisão das grandes áreas em especialidades e subespecialidades médicas; valorização do diagnóstico e do tratamento das doenças, sem a devida ênfase à sua prevenção, à promoção da saúde e à atenção ao paciente.

Seguiram-se, na década de I990, novos estudos e documentos sobre educação médica, como os produzidos pela opas e os resultantes da $2^{\underline{a}}$ Conferência Mundial de Educação Médica (I993), da Conferência Andina sobre Educação Médica (1993) e do Encontro Continental de Educação Médica (1994), realizados respectivamente em Edimburgo, Cartagena e Punta del Leste (Almeida, I999).

No Brasil, nessa mesma década, o projeto desenvolvido pela Comissão Interinstitucional Nacional de Avaliação do Ensino Médico (Cinaem) e o programa UNI contribuíram para introduzir amplas transformaçóes nos currículos de cursos superiores ligados à saúde. A responsabilidade pela condução do primeiro e do segundo coube, respectivamente, à ABEM e à Fundação Kellogg, entidades que coordenaram e apoiaram o projeto EMA (Chaves \& Rosa, I990).

Ciente da necessidade de implementação de reformas nos currículos dos cursos de Medicina e reconhecendo a baixa institucionalização dos projetos IDA, a ABEM - que já havia coordenado o projeto EMA procura consolidar alianças com associaçóes médicas, educacionais e representativas de docentes e alunos, também críticas do modelo de formação vigente: Academia Nacional de Medicina, Associação Mé- 
dica Brasileira (АМв), Associação Nacional dos Médicos Residentes (Anmr), Conselho Federal de Medicina (CFM), Conselho Nacional de Secretarias Municipais de Saúde (Conasems), Conselho Regional de Medicina do Estado do Rio de Janeiro (Cremerj), Conselho Regional de Medicina do Estado de São Paulo (Cremesp), Conselho de Reitores das Universidades Brasileiras (Crub), Direção Executiva Nacional dos Estudantes de Medicina (Denem), Federação Nacional dos Médicos (Fenam) e Sindicato Nacional dos Docentes das Instituiçôes de Ensino Superior (Andes). Todas essas entidades e a própria ABEM reúnem-se e decidem constituir a Cinaem, no entendimento de que a formação do médico não é de responsabilidade exclusiva da instituição superior, mas deve ser também partilhada com o Estado e a sociedade civil.

O passo inicial da Cinaem, em I99I, foi convidar os responsáveis por cursos de Medicina a participarem de um projeto multicêntrico com três fases: $\mathrm{I}^{\mathrm{a}}$ ) avaliação diagnóstica da situação vigente; $2^{2}$ ) realização de oficinas de trabalho com representantes das diferentes associações para propor estratégias de intervenção nos seguintes eixos: processo de formação, docência médica, gestão de cursos e respectiva avaliação; $3^{\underline{a}}$ ) avaliaçáo do aluno.

Após a sistematização dos produtos das diferentes etapas, foi possível elaborar, em 2000, um relatório com a proposta de transformação do ensino médico (Piccini et al., 2000).

A Cinaem foi, ao mesmo tempo, um projeto científico liderado por pesquisadores e consultores conceituados e, principalmente, um movimento social, uma pesquisa-ação. Professores, alunos, pós-graduandos e gestores profissionais procederam à análise dos resultados de cada fase e, no processo de construção coletiva, permutaram conhecimentos, tornando-se agentes de transformação da educação médica.

Em io de dezembro de 1997, a Secretaria de Educação Superior (SESu) do MEC, atendendo à lei federal no 9. 3 I e à Lei de Diretrizes e Bases da Educação Nacional, promulgadas respectivamente em 1995 
(Brasil, I995) e I996, lança o edital no 4/97, no qual solicita que universidades, cursos, sociedades científicas, ordens e conselhos profissionais, de forma isolada ou conjunta, ofereçam contribuições para a elaboração das diretrizes nacionais dos cursos de graduação (Brasil, I997). Esse instrumento legal esclarecia que tais diretrizes tinham por objetivo "servir de referência para as Instituições de Ensino Superior (IES) na organização de seus programas de formação, permitindo uma flexibilidade na construçáo dos currículos plenos e privilegiando a indicação de áreas do conhecimento a serem consideradas, ao invés de estabelecer disciplinas e cargas horárias definidas" e recomendava que as modernizaçóes curriculares fossem orientadas pelos perfis profissionais demandados pela sociedade.

Democrático e inovador, o edital solicitava, ainda, que as sugestóes fossem organizadas nos seguintes tópicos: perfil desejado do formando; competências e habilidades correspondentes; conteúdos curriculares básicos e profissionais, essenciais ao desenvolvimento das mesmas competências e habilidades; estruturação modular dos currículos; e adoção de metodologias de avaliação abrangentes.

A Rede Unida reconheceu e apoiou a forma democrática com que o MEC e o Conselho Nacional de Educação encaminharam o prospecto das diretrizes curriculares, propiciando a ampla participação da sociedade. Nesse sentido, a Rede estimulara seus associados a debaterem a questão, apresentando as respectivas contribuiçôes. A partir de um trabalho de sistematização, produziu o documento "Contribuição para as Novas Diretrizes Curriculares dos Cursos de Graduação da Área da Saúde”, publicado na Revista Olho Mágico (I998) e encaminhado à SESu/MEC. Paralelamente às diretrizes específicas, o texto formulava as competências comuns aos profissionais da saúde.

A proposta elaborada pela Cinaem incluía as competências profissionais desejadas e apontava o caminho que a escola deveria trilhar no processo de formação dos futuros médicos, sustentado por um novo perfil docente e um moderno sistema de gestáo de cursos e 
avaliação. Para essa entidade, o ensino da prática médica tinha como base o processo saúde-doença e as necessidades tanto individuais e coletivas referidas pelo usuário quanto aquelas identificadas pelos profissionais de saúde.

O colegiado de diretores de escolas médicas da ABEM, de posse do documento da Cinaem, ampliou-o na relação das competências profissionais; na pormenorização dos conteúdos essenciais, não expressos obrigatoriamente em disciplinas isoladas, mas relacionados com todo o processo saúde-doença do cidadão, da família e da comunidade, e também incorporados à realidade epidemiológica, proporcionando a integralidade das açóes do cuidar em Medicina; e na estrutura curricular, que deveria propiciar a interaçáo ativa do aluno com usuários e profissionais de saúde desde o início do curso. Desse modo, possibilitar-se-ia ao aluno lidar com problemas reais, assumir responsabilidades crescentes como agente prestador de cuidados e atenção, compatíveis com seu grau de autonomia - que se consolidaria na graduação, com o internato -, e também vincular a formação médico-acadêmica às necessidades sociais da saúde.

O documento final da Comissão de Especialistas da SEsu mostrou várias incoerências em relação ao edital nº 4/97, não tendo contemplado devidamente as três propostas anteriores, que eram complementares sob alguns aspectos - mas não antagônicas - e incorporavam posturas modernas.

A diretoria da ABEM, articulada com a Rede Unida, a Secretaria de Políticas do Ministério da Saúde - na época, claramente interessada na questão da formação de recursos humanos para o sus - e a OPAS, negociou com a Diretoria de Políticas da SESu/MEC um prazo adicional para a apresentação de uma proposta única.

A compatibilização entre os conteúdos foi realizada durante uma oficina que reuniu a ABEM, a Cinaem e a Rede Unida com representantes da Comissão de Especialistas; o texto final foi encaminhado no dia 2 de outubro de 2000 à SESu, que o reencaminhou à Câmara 
de Ensino Superior (CEs), do Conselho Nacional de Educação. Com pequenas alteraçóes, dele se originou o parecer n⿳丷ㅡ. I. 33/o I, aprovado no plenário do Conselho Nacional de Educação e posteriormente publicado no Diário Oficial da Uniáo em 3 de outubro de 200 I.

A transformação do ensino médico, até então estimulada por movimentos da sociedade civil, passou a ser uma obrigação legal. Obrigação de alcançar a formação generalista, humanista, crítica e reflexiva do profissional médico, desenvolvendo-se, entre outras, as seguintes competências:

a. Promover a saúde integral do ser humano e atuar, de acordo com princípios éticos, no processo saúde-doença, com medidas de prevenção, recuperação e reabilitação da saúde, na perspectiva da integralidade da assistência, demonstrando senso de responsabilidade social e compromisso com a cidadania.

b. Atuar nos diferentes níveis de atendimento à saúde, com ênfase no primário e no secundário; diagnosticar e tratar corretamente as principais doenças do ser humano em todas as fases do ciclo biológico, tendo como critérios sua prevalência e potencial mórbido, bem como a eficácia da ação médica.

c. Reconhecer suas limitações e encaminhar, de modo apropriado, pacientes portadores de problemas que fujam ao alcance de sua formação geral.

d. Otimizar o uso dos recursos propedêuticos, valorizando o método clínico em todos os seus aspectos.

e. Exercer a Medicina utilizando procedimentos diagnósticos e terapêuticos com base em evidências científicas.

f. Utilizar adequadamente recursos semiológicos e terapêuticos, validados cientificamente, que sejam contemporâneos e hierarquizados, para a atenção integral à saúde.

g. Reconhecer a saúde como direito e atuar de forma a garantir a integralidade da assistência, entendida como o conjunto articulado 
e contínuo de açôes e serviços preventivos e curativos, individuais e coletivos, exigidos para cada caso, em todos os níveis de complexidade do sistema.

Paralelamente aos desafios já mencionados no início deste texto, temos agora posto o desafio de formar um profissional imbuído de uma prática ampliada com atuação "orientada por uma visão mais integrada, intersetorial, visando ampliar a estratégia de promoção, e pautada pela perspectiva da responsabilidade sanitária como elemento norteador das práticas em saúde" (Oliveira \& Koifman, 2004). De imediato, podemos dizer que cumpre saber ensinar, auxiliar e orientar a construção de competências profissionais como as anteriormente referidas; para desenvolvê-las precisamos promover a integração do processo de ensino com o de produção de saúde em todos os níveis de atenção.

Isto significa deslocar de cima para baixo o atual modelo de formação médica, reproduzindo-se a afirmação de Donald Shön, ao referirse à relação entre prática competente e prática profissional. Para esse autor, a prática competente - na concepção atual - é mais que a prática profissional advinda exclusivamente do conhecimento sistemático, de preferência científico, tendo perdido o referencial artístico, pelo qual se aprende fazendo (Schön, 2000).

O Comitê de Revisão de Qualidade Educacional da Austrália, citado por Santana e colaboradores (Santana et al., [s.d.]), define competência como a "capacidade de aplicar adequadamente conhecimento e habilidades para alcançar um determinado resultado em um contexto concreto". Existem inúmeras outras definiçôes, mais complexas, mas o importante é reconhecer que "ser competente para" exige mais que "saber sobre": ser competente é saber sobre (domínio cognitivo), saber fazer (domínio psicomotor) e saber ser (domínio afetivo). O ensino de competências compreende a utilização de metodologias ativas de aprendizagem, orientadas para a autonomia, e o estabelecimento de uma relação de organicidade com o contexto da sociedade a que se 
aplica, conforme as proposiçóes de Paulo Freire e outros educadores. Requer também o concurso de múltiplos saberes - saberes das disciplinas acadêmicas, saberes dos profissionais de serviço e saberes do indivíduo e da comunidade. Nesse processo de ensino-aprendizagem, mestre e aluno aprendem e produzem conhecimento novo.

A introdução isolada de alguns dos componentes desse conjunto, tais como a prática extramuros, as metodologias ativas de ensinoaprendizagem, a interdisciplinaridade e a produção de conhecimento, correlaciona-se com inovaçôes no ensino médico; a vigência do conjunto significa construir competências, significa mudança paradigmática.

Várias escolas médicas têm-se mobilizado na direção da transformação. Predominam, ainda, as inovaçóes mais voltadas para as novas metodologias e menos para a articulação com os serviços, como mostram os recentes resultados do projeto "Avaliação das Tendências de Mudanças das Escolas Médicas Brasileiras", conduzido pela Comissão de Avaliação das Escolas Médicas (CAEM), da Associação Brasileira de Educação Médica (ABEM, [s.d.]), e dos projetos contemplados pelo Programa Nacional de Reorientação da Formação Profissional em Saúde - Pró-Saúde (Brasil, 2005).

A consolidação das DCN pressupóe que a escola médica avance na reorientação do processo de formação, integrando-se aos serviços de saúde, com o objetivo de formar profissionais aptos a responder às necessidades da população brasileira e à operacionalização do sus.

\section{REFERÊNCIAS BIBLIOGRÁFICAS}

Almeida, M. J. de. I999. Educação Médica e Saúde: Possibilidades de Mudança. Rio de Janeiro, Associação Brasileira de Educação Médica.

Andrade, L. O. M. de; Pontes, R. J. S. \& Martins Junior, T. 2000. "A Descentralização no Marco da Reforma Sanitária no Brasil". Revista Panamericana de Salud Pública, 8 (I-2), pp. 85-9I. 
Arouca, Sérgio. 2002. "O Eterno Guru da Reforma Sanitária”. Radis - Comunicação em Saúde: Radis Entrevista [periódico na Internet]. Out. [citado 27 fev. 2007]. Disponível em: http://bvsarouca.cict.fiocruz.br/lildbi/ docsonline/9/o/IO9-RADIS_ENTREVISTA.doc.

Associação Brasileira de Educação Médica - ABEm. Comissão de Avaliação das Escolas Médicas - CAEM. s.d. Avaliação de Tendências de Mudanças no Curso de Graduação das Escolas Médicas Brasileiras: Projeto. Brasília (DF), ABEM. Disponível em http://www.abem-educmed.org.br/caem/projeto. pdf, acesso em 5 fev. 2007.

Brasil. I988. Presidência da República. Constituição da República Federativa do Brasil de 1988, Brasília (DF). Disponível em http://www.planalto. gov.br/ccivil_03/Constituicao/Constitui\%C3\%A7ao.htm, acesso em I 5 mar. 2007.

Brasil. I 995. Presidência da República. "Lei no 9. I 3 I, de 24 de novembro de I995. Altera dispositivos da lei n⿳0 4.024, de 20 de dezembro de I96 I, e dá outras providências”. Diário Oficial da República Federativa do Brasil. Brasília (DF), 25 nov. Disponível em http://www.planalto.gov.br/ccivil_03/ Leis/QUADROS/I995.htm, acesso em 30 mar. 2007.

Brasil. I 996. Presidência da República. "Lei no 9.394, de 20 de dezembro de I996. Estabelece as Diretrizes e Bases da Educação Nacional”. Diário Oficial da República Federativa do Brasil, Brasília (DF), 23 dez. Disponível em http://www.planalto.gov.br/ccivil_03/Leis/QUADRO/I996.htm, acesso em 30 mar. 2007.

Brasil. I 997. Ministério da Educação e do Desporto. Secretaria de Educação Superior. "Edital no 4/97. Convoca as Instituiçôes de Ensino Superior a Apresentarem Propostas para as Novas Diretrizes Curriculares dos Cursos Superiores”. Brasília (DF). Disponível em http://portal.mec.gov.br/sesu/ arquivos/pdf/eo4.pdf, acesso em 3 mar. 2007.

Brasil. 200 I. Ministério da Educação e Cultura. Conselho Nacional de Educação. Câmara de Educação Superior. Parecer CNE/CES nº I.I33, de 7 de agosto de 200 I. Institui as Diretrizes Curriculares Nacionais dos Cursos de Graduação em Enfermagem, Medicina e Nutrição. Brasília (DF). Disponí- 
vel em http://portal.mec.gov.br/cne/arquivos/pdf/CES I I33.pdf, acesso em I 2 mar. 2007.

Brasil. 2005. Ministério da Saúde. Ministério da Educação. Programa Nacional de Reorientação da Formação Profissional em Saúde - Pró-Saúde. Brasília (DF). Disponível em http://www.abem-educmed.org.br/pro_saude/publicacao_pro-saude.pdf, acesso em 5 fev. 2007.

Chaves, M. \& Rosa, A. R. I990. Educação Médica nas Américas: o Desafio dos Anos 9o. São Paulo, Cortez.

Feuerwerker, L. C. M.; Costa, H. O. G.; Barbosa, N. \& Khalil, M. E. s.d. O Processo de Construção e de Trabalho da Rede Unida. Londrina, Rede Unida. Disponível em http://www.redeunida.org.br/producao/div_process.asp, acesso em 6 mar. 2007.

Freire, P. 200 i. Educação e Atualidade Brasileira. $2^{2}$ ed. São Paulo, Cortez.

Oliveira, G. S. \& Koifman, L. 2004. "Integralidade do Currículo de Medicina: Inovar/Transformar, um Desafio para o Processo de Formação". In: Marins, J. J. N.; Rego, S.; Lampert, J. B. \& Araújo, J. G. C. de (orgs.). Educação Médica em Transformação: Instrumentos para a Construção de Novas Realidades. São Paulo, Hucitec.

Organização Mundial da Saúde. 1978. Declaração de Alma-Ata. Conferência Internacional sobre Cuidados Primários de Saúde. Alma-Ata, URss, 6- I 2 set. Disponível em http://www.opas.org.br/coletiva/uploadArq/Alma-Ata.pdf, acesso em I 2 mar. 2007.

Paim, J. S. I992. "A Reforma Sanitária e a Municipalização". Revista Saúde e Sociedade, 2(I), pp. 29-42.

Piccini, R. X.; Facchini, L. A. \& Santos, R. C. (orgs.). 200o. Preparando a Transformação da Educação Médica Brasileira: Projeto Cinaem III Fase - Relatório 1999-2000. Pelotas, Universidade Federal de Pelotas.

"Rede Unida: Contribuição para as Novas Diretrizes Curriculares dos Cursos de Graduaçấo da Área da Saúde”. 1998. Revista Olho Mágico. Disponível em http://www.ccs.uel.br/olhomagico/Ni6/home.htm, acesso em I 2 mar. 2007.

Santana, J. P. de; Campos, F. E. de \& Sena, R. R. de. s.d. Formação Profissional em Saúde: Desafios para a Universidade. Brasília (DF), Organização 
Pan-Americana da Saúde. Disponível em http://www.opas.org.br/rh/publicacoes/textos_apoio/ACF2 I I 4.pdf, acesso em I 5 mar. 2007.

Santos, B. de S. i995. Pela Mão de Alice. São Paulo, Cortez.

Schön, D. A. 2000. Educando o Profissional Reflexivo: um Novo Design para o Ensino e a Aprendizagem. Porto Alegre, Artes Médicas Sul.

Silva, A. M. dos S. 1999. "A Universidade no Limiar do Século xxi". Interface Comunicação, Saúde, Educação, 3(4), pp. I I-26. Disponível em http:// www.interface.org.br/revista4/ensaio I.pdf, acesso em I2 mar. 2007.

“The Edinburgh Declaration”. i988. Revista Médica de Chile. i i6(ıо), pp. I075-1076.

Toledo, C. N. de. 1997. Iseb: Fábrica de Ideologias. $2^{\mathrm{a}}$ ed. Campinas, Unicamp. de. 2005. "50 Anos de Fundaçấo do Iseb". Jornal da Unicamp, Campinas, 8-I4 ago. Disponível em http://www.unicamp.br/unicamp/ unicamp_hoje/ju/agosto2005/ju296pag I I.html.

United Nations Educational Scientific and Cultural Organization. Unesco. 1998. World Declaration on Higher Education for the Twenty-first Century: Vision and Action and Framework for Priority Action for Change and Development in Higher Education, Adopted by the World Conference on Higher Education. Paris, 9 out. Disponível em http://portal.unesco.org/education/en/ev.php-URL_ID=IO699 \&URL_DO=DO_TOPIC\&URL_SECTION=20 I . html, acesso em I 2 mar. 2007. 
